\title{
Observations on the ${ }^{32} \mathrm{P}$ uptake test
}

\author{
H. MOSELEY AND W. S. FOULDS \\ From the West of Scotland Health Boards, Department of Clinical Physics and Bio-Engineering, \\ Glasgow, and the Tennent Institute of Ophthalmology, the University, Glasgow
}

SUMMARY The results of the ${ }^{32} \mathrm{P}$ uptake test in the diagnosis of intraocular malignancies is presented. The tests were carried out with the use of a newly developed eye probe. A quantitative comparison of different control sites is described, and a statistical analysis has been conducted on the counts obtained during the uptake procedure.

Some investigators have questioned the validity of the radioactive phosphorus $\left({ }^{32} \mathrm{P}\right)$ uptake test in the diagnosis of intraocular malignancies because of the presence of false negative or false positive results. ${ }^{1-3}$ However, its usefulness has been demonstrated by the publication of large series with success rates of $96 \%$ and over. ${ }^{4-7}$

The basis of the test is that neoplastic tissue has an increased rate of phosphate uptake and retains the isotope longer than non-neoplastic tissue. Care must be exercised both in the performance of the test and in the interpretation of the results. To this end published papers which indicate the usefulness of the test also emphasise some relevant practical considerations.

The aims of the present paper are (1) to report on the authors' experience with the ${ }^{32} \mathrm{P}$ test, (2) to assess an experimental eye probe, (3) to describe a quantitative comparison of different control sites,

Correspondence to Mr H. Moseley, West of Scotland Health Boards, Department of Clinical Physics and Bio-Engineering, 11 West Graham Street, Glasgow G4 9LF. and (4) to conduct a statistical analysis on the counts obtained during the uptake procedure.

\section{Materials and method}

The present investigation was carried out with a beta-sensitive semiconductor detector developed at the Instrumentation and Applied Physics Division, Atomic Energy Research Establishment, Harwell, England. The technical details have been published elsewhere. ${ }^{8}$ The dectector is a planar, thermally diffused p-n junction, with a diameter of $8 \mathrm{~mm}$, a thickness of $0.5 \mathrm{~mm}$, and a particle window of $50 \mu \mathrm{m}(0.002 \mathrm{in})$ thickness stainless steel. At an operating bias of 100 volts the depletion depth is $300 \mu \mathrm{m}$ to $500 \mu \mathrm{m}$ and the capacitance is approximately $8 \mathrm{pF}$. The preamplifier is contained within the handle for optimum signal to noise characteristics. The probe was connected to a modified J. and P. 65/063 power unit and 95/2151 amplifier and from there to a digital display (Fig. 1). (An electronic system is now available from Harwell to use with these probes.) The sensitivity of the instru-
Fig. 1 The semiconductor eye probe with the amplifier and digital display used in the present investigation.

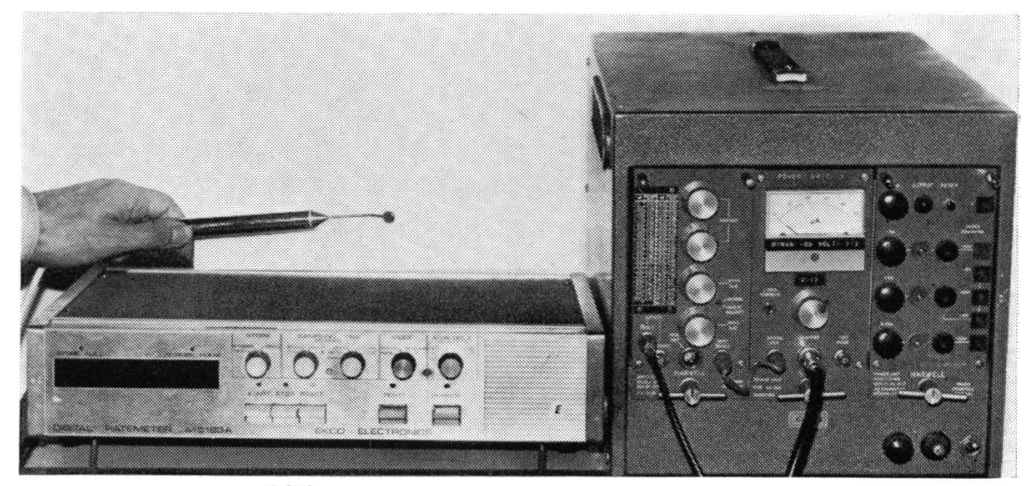


ment is 0.6 counts $/ \mathrm{s} / \mathrm{nCi} / \mathrm{ml}$ at 70 volts bias, which is the voltage rating at which the instrument was operated.

In patients to be tested eight $\mu \mathrm{Ci}$ of disodium ${ }^{32}$ phosphate per $\mathrm{kg}$ body weight up to a maximum dose of $500 \mu \mathrm{Ci}$, was injected intravenously in $5 \mathrm{ml}$ saline. Counts were taken at 24 and 48 hours after injection. The probe was positioned on the sclera over the site of the lesion with minimal pressure, and 2 separate 100 second counts were recorded. The mean of these 2 values was taken as the measured test count. For lesions which were otherwise inaccessible the conjunctiva was usually incised to facilitate accurate localisation of the probe. Counts were also taken over 2 separate control sites. One of these was from a site in the other eye corresponding to the position of the lesion in the fellow eye, and the other was a site in the same eye diametrically opposite the lesion. 100 second counts were taken from each area in turn and then repeated. A mean count of the 4 readings was usually used as the control value.

Before a centre can establish its own criteria for positivity it is necessary to gain experience with the test. Initially, therefore, a $60 \%$ increase in counts over the lesion as compared with the control site ${ }^{9}$ was considered positive. When a lesion failed to produce a difference of this magnitude, a careful scan was carried out by moving the probe in relation to the lesion and taking a series of 10 second counts during the process. If an active area was located by this method, 10 consecutive 10 second counts from this area were summed.

The $^{32} \mathrm{P}$ uptake is defined by the equation ${ }^{910}$ :

$$
\mathrm{U}=\frac{\mathrm{T}-\mathrm{C}}{\mathrm{C}} \times 100
$$

where $\mathrm{U}={ }^{32} \mathrm{P}$ uptake, $\mathrm{T}=$ average counts at test site, $\mathrm{C}=$ average counts at control site.

\section{Results}

The test was performed on 46 patients. Three patients had a lesion in the iris, while in the remaining 43 patients the lesion was posteriorly situated.

Of the 43 posteriorly placed lesions the majority (33) had the clinical features of malignant melanoma of the choroid, as assessed by ophthalmoscopy, tests of visual function, fluorescein angiography, and ultrasound. In line with current practice some of the smaller malignant melanomas were kept under observation, so that histological confirmation of the diagnosis was made in only 25 cases. Ten cases were considered to have benign lesions. These included 2 lesions removed by local choroidectomy and shown histologically to be benign adenomas,
2 benign naevi, 2 annular serous choroidal detachments, 1 choroidal haemorrhage, 1 retinal and choroidal detachment, 1 serous retinal detachment, and 1 retinoschisis.

With the exclusion of results from iris lesions, since they have been shown elsewhere 9 to be inaccurate and are no longer routinely measured at this centre, results from 2 eyes showing a severe inflammatory reaction which was thought to invalidate the test, and results from 4 posteriorly placed lesions where incision of the conjunctiva was considered to be inappropriate, there were 37 cases available for evaluation of the test. The results in these $\mathbf{3 7}$ cases are shown graphically in Fig. 2.

At 24 hours there was considerable overlap

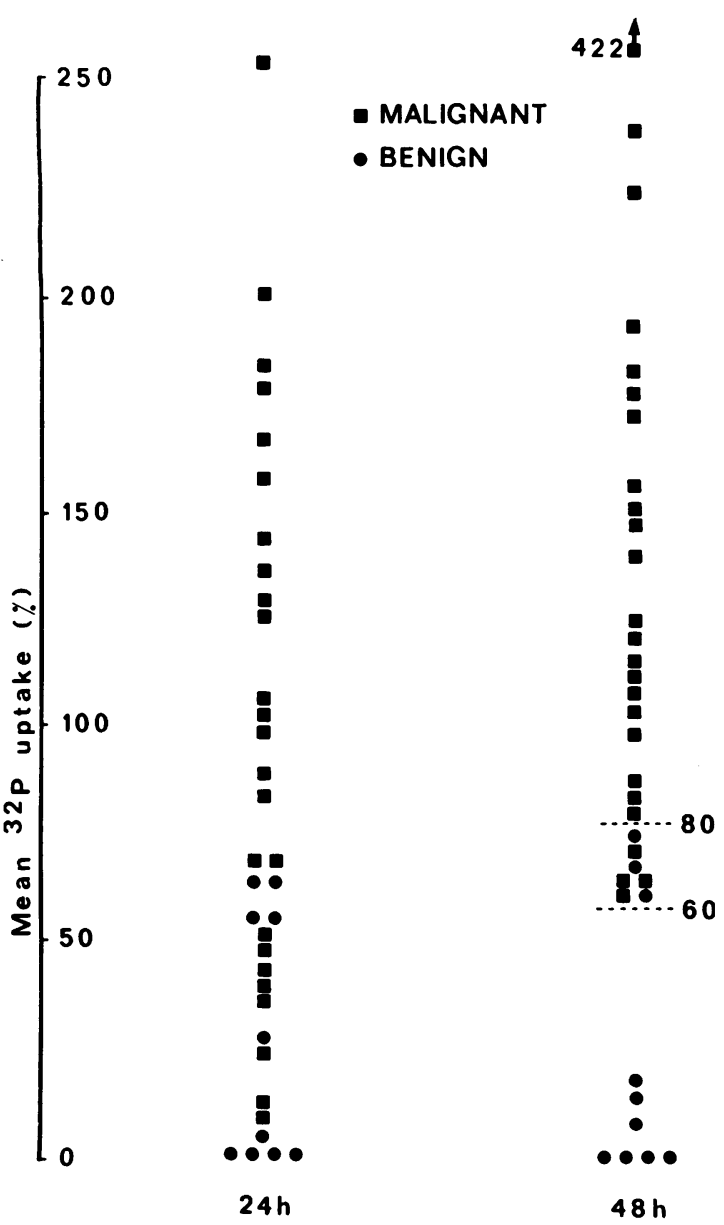

Fig. 2 The mean ${ }^{32} P$ uptakes obtained at $24 h$ and $48 \mathrm{~h}$ after administration of the isotope. Results are from histologically verified or clinically diagnosed malignant and benign lesions. Thirty-one of the 37 cases plotted had the test performed both at $24 \mathrm{~h}$ and at $48 \mathrm{~h}$. The $60 \%$ and $80 \%$ uptake levels are shown at $48 \mathrm{~h}$. 
between counts from benign and malignant lesions, all of the benign lesions and 10 of the malignant lesions $(40 \%)$ having uptakes of less than $80 \%$.

At 48 hours the separation of the 2 groups was much clearer, 21 of the malignant lesions (84\%) having uptakes in excess of $80 \%$, while all of the benign lesions had counts which were less than $80 \%$ above control values. In 7 of the 10 benign lesions counts were within $20 \%$ of control values, but in 2 benign adenomas and 1 serous choroidal detachment uptakes lay in the range $60-80 \%$. Similarly, 4 of the 25 malignant lesions gave results which lay within this same range.

The mean count in 100 seconds from all the test eyes was $1202 \pm 697$ (SD) compared with $836 \pm 430$ for control sites in the affected eye and $693 \pm 377$ for control sites in the fellow eye. The values of mean uptake using a control site in the affected eye as compared with a control site in the fellow eye are shown in Table 1 . At 24 hours there was a $29 \%$ difference in the mean uptake derived from these $\mathbf{2}$ control sites, and at $\mathbf{4 8}$ hours the difference was $40 \%$.

The change in uptake between the 24 and 48 hour measurement was also assessed in both groups of patients by placing the test results into 1 of 3 categories (Fig. 3). There were 2 benign and 2 malignant lesions in which the $\mathbf{4 8}$ hour uptake was less than the 24 hour uptake by at least $10 \%$. Five benign and 5 malignant lesions had uptakes which were within $10 \%$ at the 2 times. While there were only 3 benign lesions in which the 48 hour uptake was greater than the 24 hour uptake by at least $10 \%, 14$ malignant lesions came into this category.

\section{Discussion}

When the test was first reported, ${ }^{11}$ its reliability was limited by the difficulty in siting early detectors accurately over the lesion being investigated. Initially, counting relied on Geiger-Müller tubes which were relatively large and only suitable for anteriorly placed lesions. Smaller Geiger-Müller tubes are now available which may be used for posterior lesions. The recent development of semi-

Table 1 Mean ${ }^{32} P$ uptake $\pm S E M$ obtained at $24 h$ and $48 h$ with a control site either in the affected eye or in the fellow eye

\begin{tabular}{llc}
\hline & \multicolumn{2}{l}{ Mean ${ }^{32} P$ uptake \pm SEM } \\
\cline { 2 - 3 } & $\begin{array}{l}\text { Control site in } \\
\text { affected eye }\end{array}$ & $\begin{array}{c}\text { Control site in } \\
\text { fellow eye }\end{array}$ \\
\hline $24 \mathrm{~h}$ & $60 \pm 9$ & $80 \pm 11$ \\
$48 \mathrm{~h}$ & $77 \pm 11$ & $115 \pm 17$ \\
\hline
\end{tabular}

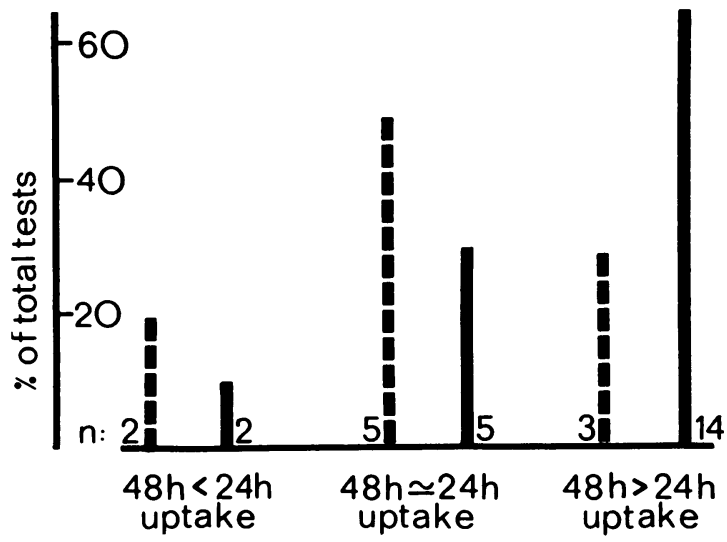

Fig. 3 The \% distribution of benign lesions (dashed line) and malignant lesions (continuous line) according to whether the $48 h$ uptake was less than the $24 h$ uptake by at least $10 \%$, whether the uptakes at both times were within $10 \%$, or whether the $48 \mathrm{~h}$ uptake was greater than the $24 \mathrm{~h}$ uptake by more than $10 \%$. Also shown are the actual number of tests in each category.

conductor probes such as that used in the present study have improved the reliability of the ${ }^{32} \mathrm{P}$ test, since these probes are particularly well suited as ocular detectors, being smaller, more sensitive, and more robust than Geiger-Müller tubes.

The experimental probe used in this study has proved to be reliable in use and has withstood ethylene oxide sterilisation at $55^{\circ} \mathrm{C}$. Moreover, its high counting efficiency has helped to improve the accuracy of the test.

Measured counts of ${ }^{32} \mathrm{P}$, both at 24 hours and at 48 hours after injection, greater than $80 \%$ above mean control values were all from histologically proved or clinically diagnosed malignant melanomas. At 24 hours after injection there was a significant overlap of results from benign and malignant lesions. At 48 hours there was a clearer separation of the 2 groups in that all lesions with uptakes less than $60 \%$ were clinically benign. Lesions giving uptakes between 60 and $80 \%$ above control values included 3 benign and 4 out of 25 malignancies.

Thus at both 24 hours and 48 hours an $80 \%$ increase in uptake over control values is a strong indication of malignancy, while in addition at 48 hours a count of less than $60 \%$ above control counts strongly suggested a benign lesion. Counts between 60 and $80 \%$ above control values are equivocal.

The technique of 'scanning' the lesion with the probe to find the area of maximum activity and taking a succession of 10 second counts from this area helps to prevent false negatives. The taking of 10 consecutive 10 second counts enables the operator to detect any slight movement of the probe 
producing a fall in count. A small or inaccessible lesion or one which is not most active at its centre might otherwise be missed, and it is believed that the modified procedure reported here may help to reduce the possibility of obtaining false negative results in such cases. In some instances scanning did reveal positive uptakes which were lost during the initial 100 second count. In no case was there a comparable increase on scanning the control areas. It is to be emphasised that only consecutive counts were used in arriving at uptake values.

On examining the results from eyes with benign lesions it is apparent that the uptake values in these cases lay in 2 separate groups, those between 0 and $20 \%$ above control values, which could well be due to chance, and those in the $60-80 \%$ band, which indicated that the lesions were absorbing phosphorus at a similar level to some malignant melanomas. The 2 benign adenomas are interesting in relation to this. Two other such cases have been published in which the ${ }^{32} \mathrm{P}$ test has been performed and where in each case an uptake in excess of $60 \%$ was achieved (Table 2).

\section{CHOICE OF CONTROL SITE}

As first described, the test was performed with a control site in the fellow eye. ${ }^{11}$ More recently, however, the trend has been towards using a control site or sites in the affected eye, because a generalised inflammatory reaction in the affected eye might yield a false positive result if a control site in the other eye were used for comparison. ${ }^{12}$ There has as yet been no quantitative comparison between these alternative control sites except that carried out by Van Dijk on 11 patients. ${ }^{6}$ The results in Table 1 show that there is a difference in the uptake when different eyes serve as controls, and this difference increases from 24 hours to 48 hours. On average there are fewer counts at the control site in the fellow eye than in the affected eye. There may be at least 2 explanations for this. As well as the possible effect of a generalised inflammatory response in the affected eye there is also the possibility that the probe at the control site in the same

Table 2 A comparison ${ }^{32} P$ uptake values in cases of benign adenoma

\begin{tabular}{|c|c|c|c|}
\hline & \multicolumn{3}{|c|}{${ }^{32} P$ uptake } \\
\hline & $1 h$ & $24 h$ & $48 h$ \\
\hline Goldberg et al. ${ }^{10}$ & 127 & 62 & 60 \\
\hline Jarrett $^{5}$ & - & - & 122 \\
\hline Present study, case 1 & 一 & 63 & 75 \\
\hline Present study, case 2 & - & 65 & 62 \\
\hline
\end{tabular}

eye is detecting counts from the lesion itself, for although the mean range of $\beta$ particles from ${ }^{32} \mathrm{P}$ is $3 \mathrm{~mm}$ the maximum range is 7 to $8 \mathrm{~mm}$. The raised count at a control site in the same eye from this latter cause might obscure the difference between control and test counts and lead to a false negative result. Because the use of a control site in the fellow eye might, as already explained, lead to a false positive result, in the uptakes quoted in the present paper a mean control count from sites in both eyes was used.

\section{REPEATABILITY}

On each occasion two measurements were taken at ostensibly the same site. The scatter in the differences between these 2 values is a result of 2 factors. One is due to the Poisson distribution, which is a feature of all radioactive decay processes; this is a counting error. The other may be termed a positioning or location error resulting from the impossibility of placing a probe in exactly the same position for the 2 successive counts. It may be shown that for the mean counts obtained the standard deviation of the difference in 2 counts on the basis of the counting error alone is $4 \%$ for the test counts, $5 \%$ for control sites in the same eye, and 5\% for control sites in the fellow eye. Although the most probable value of the difference in the 2 reading at the same site is zero, the mean value of the difference with regard to the counting error is the standard deviation of the difference, i.e., 4 to $5 \%$. The mean values of the differences actually obtained were $12 \%$ for the test counts, $13 \%$ for the control sites in the same eye, and $14 \%$ for control sites in the fellow eye. The difference between the total error and the counting error, some $8 \%$, is the positioning error, and this is relatively constant for the three different counting locations.

\section{Conclusion}

Carefully used, the ${ }^{32} \mathrm{P}$ test employing the solid state detector described in this paper is capable of distinguishing clearly between the majority of benign and malignant intraocular lesions. Two benign adenomas and 1 case of serous detachment of the choroid investigated showed accumulation of ${ }^{32} \mathrm{P}$ similar to that encountered in a minority of malignant melanomas. The majority of malignant tumours, however, showed uptakes in excess of $80 \%$ of control values, a level which was reached by none of the benign cases.

References

${ }^{1}$ Robertson DM. Radioactive phosphorus uptake tes ting of choroidal lesions. Br J Ophthalmol 1976; 60: 835-9. 
${ }^{2}$ Shammas HF, Burton TC, Weingeist TA. False-positive results with the radioactive phosphorus test. Arch Ophthalmol 1977; 95: 2190-2.

${ }^{3}$ Zakov ZN, Smith TR, Albert DM. False-positive ${ }^{32} \mathrm{P}$ uptake tests. Arch Ophthalmol 1978; 96: 2240-3.

'Vogel MH, Strotges MW. Der wert des ${ }^{38}$ P-testes bei der diagnose intraokularer aderhautmelanome. Klin Monatsbl Augenheilk 1971; 159: 375-82.

'Jarrett WH. Ten years' experience with radioactive phosphorus uptake test in the diagnosis of uveal malignancy. In: Croll MN, Brady LW, Carmichael P, Wallner RJ, eds. Nuclear Ophthalmology. New York: John Wiley, 1976.

'Van Dijk RA. The ${ }^{32} \mathrm{P}$ test and other methods in the diagnosis of intraocular tumours. The Hague: Dr W. Junk, 1978.

${ }^{7}$ Shields JA. Accuracy and limitations of the ${ }^{32} \mathrm{P}$ test in the diagnosis of ocular tumours: an analysis of 500 cases. Ophthalmology 1978; 85: 950-66.
${ }^{8}$ Allsworth FL, Awcock ML, Howes JH. (1975). A design of rugged nuclear radiation detector for medical and biological applications. Harwell report AERE R7878 available from the Library, AERE, Harwell, Didcot, Oxon OX11 ORA, England.

${ }^{9}$ Hagler WS, Jarrett WH, Humphrey WT. The radioactive phosphorus uptake test in diagnosis of uveal melanoma. Arch Ophthalmol 1970; 83: 548-57.

${ }^{10}$ Goldberg B, Tabowitz D, Kara GA, Zavell S, Espiritu R. The use of ${ }^{33} \mathrm{P}$ in the diagnosis of ocular tumours. Arch Ophthalmol 1961; 65: 196-211.

"Thomas CI, Krohmer JS, Storaasli JP. Detection of intraocular tumours with radioactive phosphorus. Arch Ophthalmol 1952; 47: 276-86.

${ }^{12}$ Ruiz RS, Howerton EE. ${ }^{32} \mathrm{P}$ testing for posterior segment lesions. In: Croll MN, Brady LW, Carmichael P, Wallner RJ, eds. Nuclear Ophthalmology. New York: John Wiley, 1976. 